\title{
Efficacy of clonidine in patients with essential hypertension with neurovascular contact of the rostral ventrolateral medulla
}

\author{
Takao Sakuma ${ }^{1}$, Satoshi Morimoto ${ }^{1}$, Yasuko Aota ${ }^{1}$, Nobuyuki Takahashi ${ }^{1}$, Nagaoki Toyoda ${ }^{1}$, Atsushi Kosaki ${ }^{1}$, \\ Minoru Maehara ${ }^{2}$, Noboru Tanigawa ${ }^{2}$, Koshi Ikeda ${ }^{2}$, Satoshi Sawada ${ }^{2}$, Toshiji Iwasaka ${ }^{1}$
}

The rostral ventrolateral medulla (RVLM) is an important center for regulation of sympathetic nerve activity. Several clinical studies have suggested an association between neurovascular contact (NVC) of RVLM and essential hypertension. Microvascular decompression (MVD) of RVLM decreases blood pressure (BP) in hypertensive patients with NVC of this region. Therefore, MVD could be a useful therapeutic strategy to reduce BP in these patients. However, as MVD is an invasive procedure, it is worthy to seek useful antihypertensive agents for hypertensive patients with NVC. It is reported that sympathetic nerve activity is elevated in patients with hypertension accompanied by NVC of RVLM. It is anticipated that sympatholytic agents could be effective in lowering BP in these patients. In this study, we investigated the efficacy of clonidine, an $\alpha 2$ adrenergic agonist, in essential hypertensives with NVC of RVLM. Thirty consecutive essential hypertensive patients with NVC and 30 consecutive essential hypertensive patients without contact were treated with clonidine for 4 weeks, and decreases in BP and plasma norepinephrine levels were compared between the two groups. Decreases in BP and plasma norepinephrine levels were significantly greater in patients with NVC than in those without contact. These results suggest that clonidine exhibits significantly greater reductions of BP and sympathetic nerve activity in essential hypertensive patients with NVC compared with those without contact of the rostral ventrolateral medulla.

Hypertension Research (2010) 33, 633-637; doi:10.1038/hr.2010.41; published online 9 April 2010

Keywords: essential hypertension; $\alpha 2$ adrenergic agonist; clonidine; RVLM; sympathetic nerve activity

\section{INTRODUCTION}

Neurovascular compression has been widely accepted as a cause of trigeminal neuralgia and hemifacial spasm. In the majority of patients, an ectatic and elongated artery has been found in association with these syndromes. In trigeminal neuralgia and hemifacial spasm, neurovascular compression is mainly caused by the superior cerebellar artery and anterior inferior cerebellar artery, respectively. Microvascular decompression (MVD) is an appropriate technique to relieve the pain associated with these syndromes. ${ }^{1-4}$

The rostral ventrolateral medulla (RVLM) is an important center for the regulation of sympathetic and cardiovascular activities. ${ }^{5,6}$ After the initial report by Jannetta and Gendell in $1978,{ }^{7}$ several clinical studies have suggested an association between neurovascular contact (NVC) of RVLM and essential hypertension (EH). ${ }^{8-15}$ Jannetta et al. ${ }^{16,17}$ have reported that MVD of RVLM decreases blood pressure (BP) in hypertensive patients with NVC of RVLM. MVD of RVLM could be a useful therapeutic strategy to reduce BP in these patients. However, because MVD is an invasive procedure, it is worthy to seek useful antihypertensive agents for hypertensive patients with NVC of RVLM. Sympathetic nerve activity (SNA) is elevated in patients with hypertension accompanied by NVC of RVLM. ${ }^{18-20}$ We have reported a patient with refractory hypertension and NVC of RVLM, who experienced prominent BP reduction by additional treatment with clonidine, ${ }^{21}$ which is an $\alpha 2$ adrenergic agonist, and elicits hypotensive and sympathoinhibitory effects by acting mainly on RVLM. ${ }^{22}$ In this study, we investigated whether clonidine is effective in lowering BP in essential hypertensives with NVC of RVLM in a group study.

\section{METHODS}

Study subjects

Subjects were selected among patients with EH who visited our hospital between April 2006 and March 2008. They were all Japanese and they all had been diagnosed as having $\mathrm{EH}$ and were under treatment with antihypertensive drugs other than $\alpha 2$ adrenergic agonists and still had a clinic BP of $\geqslant 140 /$ $90 \mathrm{~mm} \mathrm{Hg}$ on three successive office visits and/or home BP of $\geqslant 135 /$ $85 \mathrm{~mm} \mathrm{Hg}$. Patients with secondary hypertension (renal and endocrine sources of hypertension) were excluded by appropriate physical and laboratory evaluation. Subjects who had suffered a hemorrhagic stroke or cardiac infarction in the previous 6 months, those with chronic renal failure (serum creatinine of $\geqslant 1.5 \mathrm{mg}$ per $100 \mathrm{ml}$ ), pregnant women and those with peripheral vascular or malignant disease were excluded. 


\section{Measurement of clinic BP and PR}

Clinic BP and pulse rate (PR) were measured from 1100 to $1200 \mathrm{~h}$ while the patient was seated and after at least $5 \mathrm{~min}$ of rest, using an automated oscillometric sphygmomanometer (MPV3301, Nihon Kohden, Tokyo, Japan). Three measurements were obtained $2 \mathrm{~min}$ apart at each time point. The average of the second and third readings was used for all analyses.

\section{Measurement of home BP and PR}

Home BP and PR were measured in the morning and evening using an automated oscillometric sphygmomanometer according to the Japanese Society of Hypertension Guidelines for Self-Monitoring of Blood Pressure at Home; ${ }^{23}$ within $1 \mathrm{~h}$ of waking, after urination, after 1- to 2 -min rest in a seated position, before taking antihypertensive drugs and before breakfast in the morning, and before retiring and after 1- to 2-min rest in a seated position in the evening. The average of the first $\mathrm{BP}$ and PR values taken each morning and evening everyday for 7 days was used for the analysis.

\section{MRI evaluation}

Magnetic resonance imaging (MRI) studies were performed with a 1.5-T system (Signa Excite HD, GE Medical Systems, Milwaukee, WI, USA) and a neurovascular coil. The slices were axial, parallel to a line connecting the anterior commissure and posterior commissure. T2-weighted three-dimensional fast-recovery fast-spin echo images (repletion time [TR]/echo time [TE], $1500 / 15 \mathrm{msec}$; echo train length, 48) were obtained. The voxel size was $1.4 \times 0.6 \times 0.8 \mathrm{~mm}$. Two experienced radiologists $(\mathrm{KI}$ and $\mathrm{MM})$, who were blind to the individual's medical histories, assessed all scans independently to check the grade of NVC of RVLM. In instances of disagreement between the reviewers, a consensus interpretation was used for the case. NVC of RVLM was defined as an arterial vessel or vascular loop with its convexity contacting the surface of RVLM. The anterior border of RVLM was defined as the transitional point of the olivary convexity and the concavity of the retro-olivary sulcus; the posterior border was considered to be at the junction of parenchymal brain tissue and the nerve fibers. Upper and lower borders were determined by the uppermost and the lowest end of the glossopharyngeal and vagal nerve bundle entering the medulla.

\section{Study protocols}

In a preliminary study, MRI studies were performed in these subjects until 30 patients with and without NVC of the RVLM, respectively, were collected. Thereafter, 30 consecutive essential hypertensive patients with NVC of RVLM (NVC+) and 30 consecutive hypertensive patients without NVC of RVLM (NVC-) were enrolled into the main prospective study and were further evaluated.

At enrollment, we collected information on age, gender, duration of hypertension, current antihypertensive medications, smoking history, body mass index, waist circumference, urinary protein/creatinine ratio, biochemical parameters (blood urea nitrogen, creatinine, fasting blood sugar, hemoglobin Alc, lowdensity lipoprotein cholesterol, high-density lipoprotein cholesterol and triglycerides), and plasma concentration of norepinephrine (NE), renin activity (PRA), aldosterone (Ald), brachial-ankle pulse wave velocity (baPWV), an index of arterial stiffness, carotid intima-media thickness (IMT), an index of atherosclerosis, and left ventricular mass index (LVMI), an index of left ventricular hypertrophy. All patients were treated with $225 \mu \mathrm{g}$ per day of clonidine (t.i.d.) for 4 weeks. During this study, no additional treatment or change in the dose of concomitantly administered antihypertensive medications was allowed.

Clinic BP and PR, plasma NE, PRA and plasma Ald were determined again 4 weeks after treatment, and in each group, the values were compared with pretreatment values. Net changes and percentage changes in $\mathrm{BP}$ and $\mathrm{PR}$ were compared between the NVC- group and the NVC+ group. Net changes in plasma NE, PRA and PAC were also compared between these two groups.

\section{Laboratory analyses}

The concentration of protein and creatinine in random urine samples was measured by conventional methods at the clinical laboratory center of our hospital. Morning blood samples were collected from the antecubital vein after an overnight fast of $>12 \mathrm{~h}$ and after the subjects lay in a supine resting position for at least $20 \mathrm{~min}$. Serum urea nitrogen, creatinine, fasting blood sugar, hemoglobin Alc, low-density lipoprotein cholesterol, high-density lipoprotein cholesterol and triglycerides were assessed by conventional methods at the clinical laboratory center of our hospital. Plasma NE was measured by highperformance liquid chromatography with electrochemical detection by an external laboratory (SRL, Tokyo, Japan). PRA and plasma Ald were measured by radioimmunoassay by the same external laboratory.

\section{$\mathrm{ABI}$ and baPWV}

The ankle-brachial index (ABI) and baPWV values were measured using a volume-plethysmographic apparatus PWV/ABI (Omron Healthcare, Kyoto, Japan) in accordance with a methodology described elsewhere. ${ }^{24,25}$ The lower and higher values were accepted as the ABI and baPWV values, respectively.

\section{Carotid artery ultrasonography}

Carotid ultrasound examinations of the common carotid artery, bulb and internal carotid artery were performed bilaterally using the Prosound $\alpha 10$ ultrasound system (ALOKA, Tokyo, Japan). Subjects were examined in the supine position, with the head turned $45^{\circ}$ from the site being scanned. Both carotid arteries were scanned longitudinally to visualize the IMT in the far wall of the artery and the maximum IMT was taken.

\section{Echocardiography}

M-mode echocardiography was performed using Vivid Seven scanner (GE VingMed, Milwaukee, WI, USA). The left ventricular end-diastolic dimension, left ventricular end-systolic dimension, end-diastolic interventricular septal thickness and posterior wall thickness were measured on the M-mode echocardiogram. The left ventricular mass was calculated using Devereux's formula, ${ }^{26}$ and LVMI was obtained by dividing the left ventricular mass by the body surface area.

\section{Statistical analysis}

To detect an $8 \mathrm{~mm} \mathrm{Hg}$ between-group difference in systolic BP change by clonidine treatment with a power of $80 \%$ and a minimum level of significance of 0.05 , given an s.d. of $10 \mathrm{~mm} \mathrm{Hg}, 24$ patients per group were necessary. Considering that about $20 \%$ of patients could not be evaluated, a total of 60 patients were required. $\chi^{2}$-test and nonpaired Student's $t$-test were performed to assess the statistical differences between the NVC- and NVC+ groups. Paired Student's $t$-test was applied to determine the significance of differences between pre- and post-treatment values. Data are shown as mean values \pm s.d., and differences were considered statistically significant at $P<0.05$.

The study was approved by the ethics committee of Kansai Medical University. Written informed consent was obtained from all individuals before their participation in the trial. The authors had full access to the data and take responsibility for its integrity. All authors have read and agree to the paper as written.

\section{RESULTS}

\section{Study subjects}

In the preliminary study, to collect 30 essential hypertensive patients with and without NVC of RVLM, respectively, 77 patients were subjected to MRI studies. Thereafter, in the main study, 30 consecutive patients with and without NVC of RVLM, respectively, were treated with clonidine. Two of thirty essential hypertensive patients without NVC discontinued clonidine treatment due to general fatigue unrelated to BP reduction. Four of the thirty $\mathrm{EH}$ patients with NVC discontinued clonidine therapy: one patient due to general fatigue unrelated to BP reduction, two patients due to dizziness because of prominent $\mathrm{BP}$ reduction and one patient due to eczema. As a result, 28 and 26 patients were assessed in the NVC- group and NVC+ group, respectively.

\section{Changes in baseline characteristics}

Baseline characteristics are summarized in (Table 1). At baseline, age, gender, duration of hypertension, smoking status, body mass index, 
Table 1 Characteristics of the subjects

\begin{tabular}{|c|c|c|}
\hline & $\begin{array}{l}N V C-\text { group } \\
\quad(\mathrm{n}=28)\end{array}$ & $\begin{array}{c}N V C+\text { group } \\
(\mathrm{n}=26)\end{array}$ \\
\hline Age (years) & $59.3 \pm 11.5$ & $61.8 \pm 9.3$ \\
\hline Gender (male/female) & $13 / 15$ & $12 / 14$ \\
\hline Duration of hypertension (years) & $8.2 \pm 7.3$ & $9.7 \pm 9.5$ \\
\hline Smoking (yes/no) & $5 / 23$ & $4 / 22$ \\
\hline Body mass index $\left(\mathrm{kg} \mathrm{m}^{-2}\right)$ & $24.5 \pm 3.7$ & $24.0 \pm 3.8$ \\
\hline Clinic systolic blood pressure $(\mathrm{mm} \mathrm{Hg})$ & $147.9 \pm 18.3$ & $148.1 \pm 13.2$ \\
\hline Clinic diastolic blood pressure $(\mathrm{mm} \mathrm{Hg})$ & $87.5 \pm 13.8$ & $82.1 \pm 10.2$ \\
\hline Clinic pulse pressure (b.p.m.) & $77.4 \pm 11.6$ & $78.1 \pm 12.6$ \\
\hline Home systolic blood pressure (mm Hg) & $141.3 \pm 17.4$ & $142.2 \pm 14.5$ \\
\hline Home diastolic blood pressure $(\mathrm{mm} \mathrm{Hg})$ & $82.9 \pm 14.2$ & $83.3 \pm 12.9$ \\
\hline Home pulse pressure (b.p.m.) & $74.8 \pm 9.9$ & $75.5 \pm 11.3$ \\
\hline Waist circumference $(\mathrm{cm})$ & $85.8 \pm 9.6$ & $84.6 \pm 8.1$ \\
\hline Urinary protein excretion (g per g cre) & $0.28 \pm 0.32$ & $0.26 \pm 0.29$ \\
\hline Blood urea nitrogen (mg per $100 \mathrm{ml}$ ) & $13.8 \pm 4.3$ & $14.2 \pm 4.6$ \\
\hline Creatinine (mg per $100 \mathrm{ml}$ ) & $0.72 \pm 0.38$ & $0.78 \pm 0.35$ \\
\hline Fasting blood sugar (mg per $100 \mathrm{ml}$ ) & $106 \pm 32$ & $109 \pm 21$ \\
\hline Hemoglobin A1c (\%) & $5.6 \pm 0.9$ & $5.4 \pm 0.6$ \\
\hline $\begin{array}{l}\text { Low-density lipoprotein cholesterol (mg per } \\
100 \mathrm{ml} \text { ) }\end{array}$ & $129 \pm 24$ & $122 \pm 25$ \\
\hline $\begin{array}{l}\text { High-density lipoprotein cholesterol (mg per } \\
100 \mathrm{ml} \text { ) }\end{array}$ & $57 \pm 18$ & $57 \pm 11$ \\
\hline Triglyceride (mg per 100 ml) & $142 \pm 68$ & $137 \pm 53$ \\
\hline Plasma norepinephrine $(\mathrm{pg} \mathrm{ml}-1$ ) & $382 \pm 181$ & $485 \pm 198$ \\
\hline Plasma renin activity $\left(\mathrm{ng} \mathrm{ml}-1 \mathrm{~h}^{-1}\right)$ & $3.0 \pm 3.3$ & $2.8 \pm 3.5$ \\
\hline Plasma aldosterone $\left(\mathrm{pg} \mathrm{ml}^{-1}\right)$ & $63.5 \pm 68.3$ & $52.1 \pm 52.6$ \\
\hline Ankle-brachial index & $1.1 \pm 0.1$ & $1.1 \pm 0.1$ \\
\hline Brachial-ankle pulse wave velocity $\left(\mathrm{cm} \mathrm{s}^{-1}\right)$ & $1732 \pm 345$ & $1864 \pm 359$ \\
\hline Intima-media thickness (mm) & $0.88 \pm 0.35$ & $0.85 \pm 0.24$ \\
\hline Left ventricular mass index $\left(\mathrm{g} \mathrm{m}^{-2}\right)$ & $118 \pm 31$ & $118 \pm 33$ \\
\hline
\end{tabular}

Abbreviations: b.p.m., beats per minute; cre, creatinine.

NVC-, hypertensive patients without neurovascular contact of the rostral ventrolateral medulla (RVLM); NVC+, hypertensive patients with neurovascular contact of RVLM.

waist circumference, clinic $\mathrm{BP}$ and $\mathrm{PR}$, home $\mathrm{BP}$ and $\mathrm{PR}$, biochemical parameters, plasma NE, PRA, plasma ALd, ABI, baPWV, IMT and LVMI did not differ significantly between the two groups. No patients showed ABI $<0.9$. No subjects changed their smoking status during the study period. Body mass index $\left(24.7 \pm 3.5\right.$ and $24.3 \pm 3.9 \mathrm{~kg} \mathrm{~m}^{-2}$ in the $\mathrm{NVC}(-)$ and $\mathrm{NVC}(+)$ groups, respectively, after treatment), waist circumference $(85.8 \pm 9.2$ and $83.8 \pm 9.5 \mathrm{~cm})$, blood urea nitrogen $(14.3 \pm 4.8$ and $14.0 \pm 4.5 \mathrm{mg}$ per $100 \mathrm{ml})$, creatinine $(0.77 \pm 0.29$ and $0.79 \pm 0.33 \mathrm{mg}$ per $100 \mathrm{ml})$, fasting blood sugar $(102 \pm 33$ and $105 \pm 29 \mathrm{mg}$ per $100 \mathrm{ml})$, hemoglobin Alc $(5.6 \pm 0.9$ and $5.5 \pm 0.9 \%)$, low-density lipoprotein cholesterol $(132 \pm 30$ and $129 \pm 29 \mathrm{mg}$ per $100 \mathrm{ml}$ ), high-density lipoprotein cholesterol (59 \pm 17 and $59 \pm$ $21 \mathrm{mg}$ per $100 \mathrm{ml}$ ) and triglycerides $(145 \pm 73$ and $139 \pm 60 \mathrm{mg}$ per $100 \mathrm{ml}$ ) did not change significantly because of treatment. Changes in these factors did not differ significantly between the two groups. Antihypertensive agents administered before clonidine therapy were identical between the two groups (Tables 2 and 3).

\section{Changes in clinic BP and PR}

Systolic BP was significantly decreased after treatment in the NVCgroup, and both systolic and diastolic BPs were significantly reduced after treatment in the NVC+ group (Figure 1). Decreases in systolic BP were significantly greater in the NVC+ group than in the NVC- group (Figures 2a and b). Decreases in diastolic BP tended to be greater in
Table 2 Antihypertensive medications administered at baseline

\begin{tabular}{lcc}
\hline & NVC- group & NVC+ group \\
\hline Calcium channel blockers & 18 & 15 \\
Angiotensin-receptor antagonists & 16 & 12 \\
Angiotensin-converting enzyme inhibitors & 3 & 4 \\
Diuretics & 7 & 5 \\
$\alpha$-Blockers & 1 & 2 \\
$\beta$-Blockers & 3 & 4 \\
Others & 0 & 0 \\
\hline
\end{tabular}

NVC-, hypertensive patients without neurovascular contact of the rostral ventrolateral medulla (RVLM); NVC+, hypertensive patients with neurovascular contact of RVLM.

Table 3 Number of antihypertensive agents administered at baseline

\begin{tabular}{lcc}
\hline Numbet of agents & NVC- group & $N V C+$ group \\
\hline 1 & 13 & 12 \\
2 & 10 & 10 \\
3 & 4 & 2 \\
4 & 1 & 1 \\
5 & 0 & 1
\end{tabular}

NVC-, hypertensive patients without neurovascular contact of the rostral ventrolateral medulla (RVLM); NVC+, hypertensive patients with neurovascular contact of RVLM.

the NVC+ group than in the NVC- group, although there was no significant significance. PR did not show a significant change in either group (Figure 1). Changes in PR were not significantly different between the two groups (Figures $2 \mathrm{a}$ and $\mathrm{b}$ ).

\section{Changes in NE, PRA and Ald}

After treatment with clonidine, plasma NE was significantly decreased in both groups (Figure 3a). The decrease in NE was significantly greater in the NVC+ group (Figure 3b). PRA (Figure 3c) and plasma Ald (Figure 3e) did not decrease significantly after treatment with clonidine in either group. Changes in PRA (Figure 3d) and plasma Ald (Figure 3f) were not significantly different between the two groups.

\section{DISCUSSION}

In this study, we found that administration of clonidine shows significantly greater reductions of $\mathrm{BP}$ and plasma NE levels in the NVC+ group compared with the NVC- group, indicating that clonidine is effective especially in hypertensive patients with NVC of RVLM due to its inhibitory effect on SNA.

Jannetta et al. ${ }^{13,16}$ reported that most patients with cranial neuralgia and hypertension with NVC of RVLM undergoing MVD of RVLM showed prominent BP reduction. We reported a patient with $\mathrm{EH}$ and hemifacial nerve spasms who exhibited NVC of RVLM and facial nerve. ${ }^{27}$ MVD of RVLM successfully reduced BP and indices of SNA such as plasma and urine NE, low-frequency to high-frequency ratio obtained by power spectral analysis and muscle SNA. ${ }^{27}$ Interestingly, Jannetta et al. also performed MVD of RVLM in 12 patients with EH without cranial neuralgia and observed a reduction in BP in 10 of them. ${ }^{17}$ Therefore, MVD of RVLM is expected to be a useful therapeutic strategy to reduce BP in these patients. However, as MVD is a highly invasive procedure, it seems quite unlikely to be applicable in all hypertensive patients with NVC of RVLM. It is more rational to use hypotensors with higher efficacy to treat such patients. We and others have reported that essential hypertensive patients with NVC of RVLM show increased plasma levels of NE. ${ }^{18,19}$ Furthermore, 

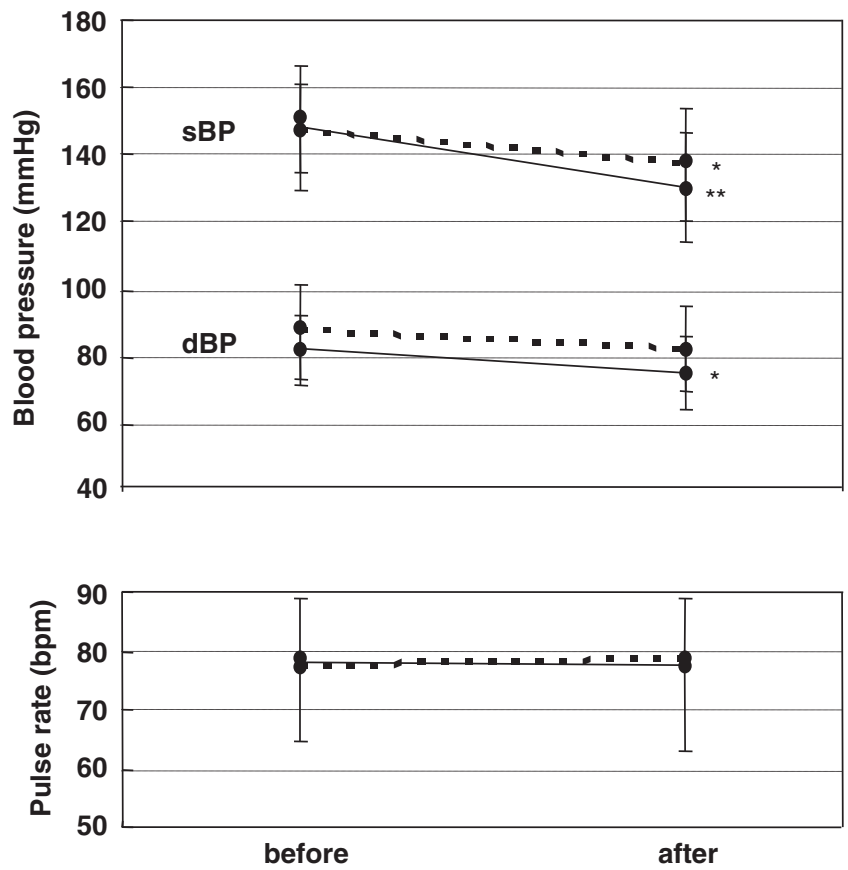

Figure 1 Clinic BP and pulse rate before and after clonidine therapy. sBP, systolic BP; dBP, diastolic BP. Dotted line: essential hypertensive patients without neurovascular contact (NVC) of the rostral ventrolateral medulla (RVLM) (NVC-, $n=28$ ); solid line: essential hypertensive patients with NVC of RVLM (NVC+, $n=26)$. ${ }^{*} P<0.0005$ and ${ }^{* *} P<0.0001$ vs. before treatment.

muscle SNA is increased in essential hypertensive patients with NVC of RVLM. ${ }^{20,28}$ We have reported a patient with refractory hypertension and NVC of RVLM, who showed BP reduction by additional treatment with clonidine. ${ }^{21}$ Therefore, drugs capable of suppressing SNA among hypotensive agents are expected to reduce BP. In this study, we assessed the efficacy of clonidine in patients with $\mathrm{EH}$ in a group study. Although plasma NE was slightly higher in the NVC+ group than in the NVC-group, the difference failed to achieve statistical significance (Figure 3a). Considering that untreated essential hypertensive patients with NVC of RVLM show significantly increased concentrations of plasma NE, ${ }^{18,19}$ it is assumed that baseline antihypertensive medications before administering clonidine affected the concentration of plasma NE. Nevertheless, additional treatment with clonidine showed greater reduction in $\mathrm{BP}$ (Figures $2 \mathrm{a}$ and $\mathrm{b}$ ) and plasma NE (Figures 3a and $\mathrm{b}$ ) in the NVC+ group, suggesting that this agent reduces BP by inhibiting SNA in essential hypertensives with NVC more than in those without NVC of RVLM when coadministered with other antihypertensive agents. However, our previous study in rats revealed that BP elevation by pulsatile compression of RVLM becomes more marked in a pressure-dependent manner. ${ }^{15}$ Therefore, we cannot rule out the possibility that a decrease in arterial stimulation of RVLM by $\mathrm{BP}$ reduction led to a further reduction of BP. At present, there is an ongoing clinical study designed to compare the pressure-lowering effects of L-type calcium antagonists, which do not have sympatholytic effects, in NVC+ and NVC- patients.

The antihypertensive drug to be first administered alone or concomitantly with other drugs should be selected from calcium channel antagonists, angiotensin-receptor blockers, angiotensin-converting enzyme inhibitors, diuretics and $\beta$-blockers. ${ }^{29}$ As clonidine is not considered as a standard drug in the treatment of hypertension, we
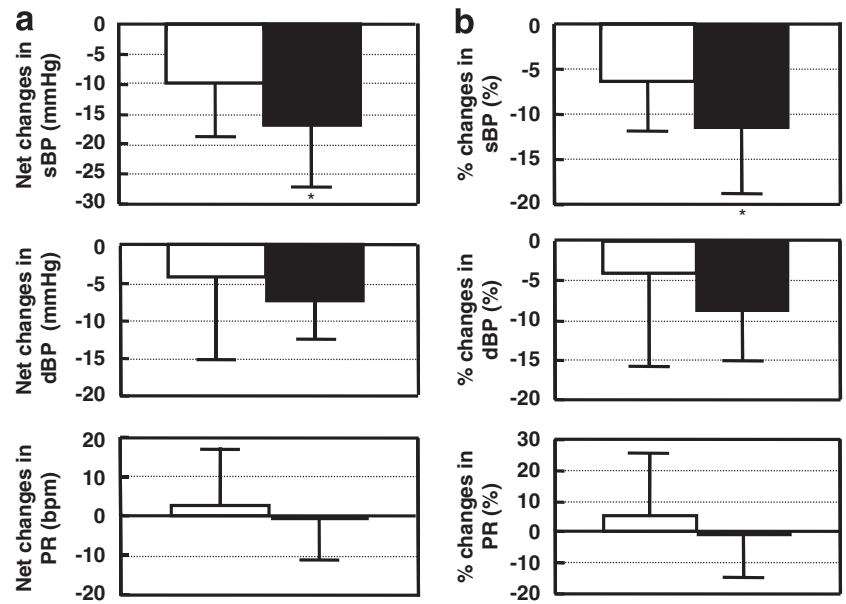

Figure 2 Changes in clinic BP and pulse rate after treatment with clonidine for 4 weeks. Open columns: essential hypertensive patients without neurovascular contact (NVC) of the rostral ventrolateral medulla (RVLM) (NVC - group, $n=28$ ); closed columns: essential hypertensive patients with NVC of RVLM (NVC+ group, $n=26$ ). ${ }^{*} P<0.05$ vs. NVC- group.
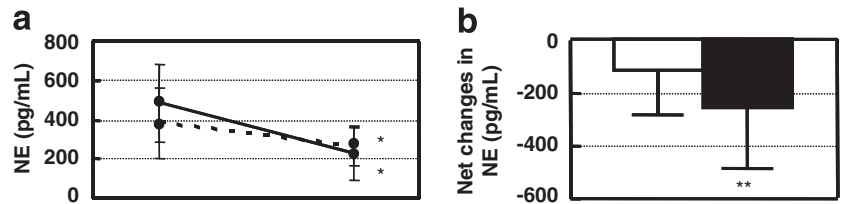

C

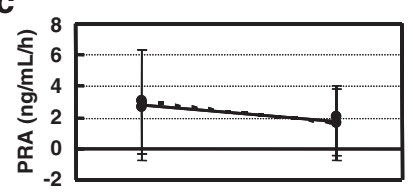

e

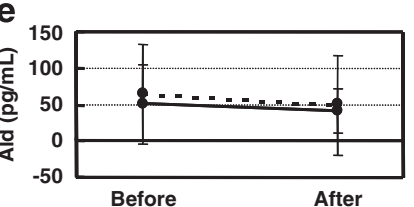

d

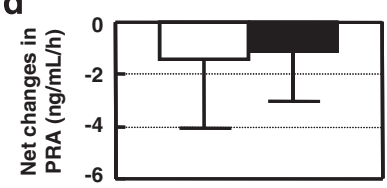

f

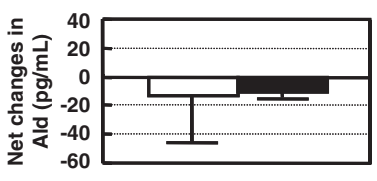

Figure 3 Plasma norepinephrine (NE) (a), renin activity (PRA) (b) and aldosterone (Ald) (c) before and 4 weeks after treatment with clonidine, as well as net changes in plasma NE (d), PRA (e) and Ald (f). Dotted lines and open columns: essential hypertensive patients without neurovascular contact (NVC) of the rostral ventrolateral medulla (RVLM) (NVC-, $n=28$ ); solid lines and closed columns: essential hypertensive patients with NVC of RVLM (NVC+, $n=26) .{ }^{*} P<0.01$ vs. before treatment; ${ }^{* *} P<0.05$ vs. NVC - group.

limited the term of clonidine administration to 4 weeks in this pilot study. Clonidine showed greater reduction in BP and SNA during this short time period, which may not be enough to observe final effect of this therapy, in the NVC+ group than in the NVC- group. Studies testing the effect of clonidine $>4$ weeks are required to determine the real efficacy of this agent. Furthermore, effects of clonidine on the regression of target organ damages such as proteinuria, arterial stiffness (baPWV), atherosclerosis (carotid IMT) and left ventricular hypertrophy (LVMI), which could not be investigated in this shortperiod study, are needed. In addition, studies examining the effects of other $\alpha 2$ adrenergic agonists such as guanfacine, guanabentz and $\alpha$ methyldopa are required. We have found that cilnidipine, a calcium 
channel antagonist that blocks not only L-type channels but also Ntype channels and inhibits SNA by inhibiting the release of NE from the peripheral sympathetic nerve endings, reduces BP and plasma NE more significantly in untreated $\mathrm{EH}$ with NVC than in those without NVC of RVLM. ${ }^{30}$ Accordingly, it is possible that any antihypertensive agent that reduces SNA activity may decrease BP especially in hypertensive patients with NVC of RVLM. To test this hypothesis, clinical studies examining the effects of other sympatholytic agents such as $\alpha$-blockers and $\beta$-blockers are also needed, and if this hypothesis is confirmed, it will become necessary to evaluate hypertensive patients for the presence of NVC of RVLM before deciding the treatment for hypertension.

In conclusion, therapy with clonidine resulted in significantly greater reductions of $\mathrm{BP}$ and SNA in essential hypertensives with NVC compared with those without NVC of RVLM, suggesting that sympatholytic agents might be especially effective in hypertensives with NVC of RVLM. It could be worthwhile to select hypotensive agents based on the presence or absence of NVC of RVLM when treating patients with $\mathrm{EH}$. As normalization of BP has been reported in hypertensive patients with NVC of RVLM after MVD, 16,17,27 hypertension due to NVC of RVLM could be classified as secondary hypertension. ${ }^{31}$ To establish this condition as a new type of secondary hypertension, it is essential to conduct further studies on its pathophysiology to establish reasonable treatment methods.

1 Jannetta PJ. Arterial compression of the trigeminal nerve at the pons in patients with trigeminal neuralgia. J Neurosurg 1967; 26: 159-162.

2 Jannetta PJ. Treatment of trigeminal neuralgia by suboccipital and transtentorial cranial operations. Clin Neurosurg 1977; 24: 538-549.

3 Haines SJ, Jannetta PJ, Zorub DS. Microvascular relations of the trigeminal nerve. An anatomical study with clinical correlation. J Neurosurg 1980; 52 381-386.

4 Jannetta PJ, Abbasy M, Maroon JC, Ramos FM, Albin MS. Etiology and definitive microsurgical treatment of hemifacial spasm. Operative techniques and results in 47 patients. J Neurosurg 1977; 47: 321-328.

5 Dampney RA, Goodchild AK, Robertson LG, Montgomery W. Role of ventrolateral medulla in vasomotor regulation: a correlative anatomical and physiological study. Brain Res 1982; 249: 223-235.

6 Oshima N, Kumagai H, Onimaru H, Kawai A, Pilowsky PM, ligaya K, Takimoto C, Hayashi K, Saruta T, Itoh H. Monosynaptic excitatory connection from the rostral ventrolateral medulla to sympathetic preganglionic neurons revealed by simultaneous recordings. Hypertens Res 2008; 31: 1445-1454.

7 Jannetta PJ, Gendell H. Neurovascular compression associated with essential hypertension. Neurosurgery 1978; 2: 165.

8 Yamamoto I, Yamada S, Sato 0. Microvascular decompression for hypertensionclinical and experimental study. Neurol Med Chir (Tokyo) 1991; 31: 1-6.

9 Kleineberg B, Becker H, Gaab MR, Naraghi R. Essential hypertension associated with neurovascular compression: angiographic findings. Neurosurgery 1992; 30: 834-841.

10 Naraghi R, Gaab MR, Walter GF, Kleineberg B. Arterial hypertension and neurovascular compression at the ventrolateral medulla. A comparative microanatomical and pathological study. J Neurosurg 1992; 77: 103-112.

11 Kleineberg B, Becker H, Gaab MR. Neurovascular compression and essential hypertension. An angiographic study. Neuroradiology 1991; 33: 2-8.

12 Akimura $T$, Furutani $Y$, Jimi $Y$, Saito $K$, Kashiwagi $S$, Kato $S$, Ito $H$. Essential hypertension and neurovascular compression at the ventrolateral medulla oblongata: MR evaluation. AJNR Am J Neuroradiol 1995; 16: 401-405.
13 Jannetta PJ, Segal R, Wolfson Jr SK. Neurogenic hypertension: etiology and surgical treatment. I. Observations in 53 patients. Ann Surg 1985; 201: 391-398.

14 Morimoto S, Sasaki S, Miki S, Kawa T, Itoh H, Nakata T, Takeda K, Nakagawa M, Kizu O, Furuya S, Naruse S, Maeda T. Neurovascular compression of the rostral ventrolateral medulla related to essential hypertension. Hypertension 1997; 30(1 Part 1): 77-82.

15 Morimoto S, Sasaki S, Miki S, Kawa T, Itoh H, Nakata T, Takeda K, Nakagawa M, Naruse S, Maeda T. Pulsatile compression of the rostral ventrolateral medulla in hypertension. Hypertension 1997; 29 (1 Part 2): 514-518.

16 Jannetta PJ, Hamm IS, Jho HD, Saiki I. Essential hypertension caused by arterial compression of the left lateral medulla: a follow-up. Perspect Neurol Surg 1992; 3: 107-125.

17 Levy EI, Clyde B, McLaughlin MR, Jannetta PJ. Microvascular decompression of the left lateral medulla oblongata for severe refractory neurogenic hypertension. Neurosurgery 1998; 43: 1-6; discussion 6-9.

18 Morimoto S, Sasaki S, Itoh H, Nakata T, Takeda K, Nakagawa M, Furuya S, Naruse S, Fukuyama R, Fushiki S. Sympathetic activation and contribution of genetic factors in hypertension with neurovascular compression of the rostral ventrolateral medulla. J Hypertens 1999; 17: 1577-1582.

19 Makino Y, Kawano Y, Okuda N, Horio T, Iwashima Y, Yamada N, Takamiya M, Takishita $\mathrm{S}$. Autonomic function in hypertensive patients with neurovascular compression of the ventrolateral medulla oblongata. J Hypertens 1999; 17: 1257-1263.

20 Smith PA, Meaney JF, Graham LN, Stoker JB, Mackintosh AF, Mary DA, Ball SG. Relationship of neurovascular compression to central sympathetic discharge and essential hypertension. J Am Coll Cardiol 2004; 43: 1453-1458.

21 Morimoto S, Aota Y, Sakuma T, Ichibangase A, Ikeda K, Sawada S, Iwasaka T. Efficacy of clonidine in a patient with refractory hypertension and chronic renal failure exhibiting neurovascular compression of the rostral ventrolateral medulla. Hypertens Res 2009; 32: 227-228.

22 Ruffolo Jr RR, Nichols AJ, Stadel JM, Hieble JP. Pharmacologic and therapeutic applications of alpha 2-adrenoceptor subtypes. Annu Rev Pharmacol Toxicol 1993; 33: 243-279.

23 Imai Y, Otsuka K, Kawano Y, Shimada K, Hayashi H, Tochikubo O, Miyakawa M, Fukiyama K. Japanese Society of Hypertension (JSH) Guidelines for Self-Monitoring of Blood Pressure at Home. Hypertens Res 2003; 26: 771-782.

24 Yamashina A, Tomiyama H, Takeda K, Tsuda H, Arai T, Hirose K, Koji Y, Hori S, Yamamoto $Y$. Validity, reproducibility, and clinical significance of noninvasive brachialankle pulse wave velocity measurement. Hypertens Res 2002; 25: 359-364.

25 Morimoto S, Yurugi T, Aota Y, Sakuma T, Jo F, Nishikawa M, Iwasaka T, Maki K. Prognostic significance of ankle-brachial index, brachial-ankle pulse wave velocity, flow-mediated dilation, and nitroglycerin-mediated dilation in end-stage renal disease. Am J Nephrol 2009; 30: 55-63.

26 Devereux RB, Alonso DR, Lutas EM, Gottlieb GJ, Campo E, Sachs I, Reichek N. Echocardiographic assessment of left ventricular hypertrophy: comparison to necropsy findings. Am J Cardiol 1986; 57: 450-458.

27 Morimoto S, Sasaki S, Takeda K, Furuya S, Naruse S, Matsumoto K, Higuchi T, Saito M, Nakagawa M. Decreases in blood pressure and sympathetic nerve activity by microvascular decompression of the rostral ventrolateral medulla in essential hypertension. Stroke 1999; 30: 1707-1710.

28 Sendeski MM, Consolim-Colombo FM, Leite CC, Rubira MC, Lessa P, Krieger EM. Increased sympathetic nerve activity correlates with neurovascular compression at the rostral ventrolateral medulla. Hypertension 2006; 47: 988-995.

29 Ogihara T, Kikuchi K, Matsuoka H, Fujita T, Higaki J, Horiuchi M, Imai Y, Imaizumi T, Ito S, Iwao H, Kario K, Kawano Y, Kim-Mitsuyama S, Kimura G, Matsubara H, Matsuura H, Naruse M, Saito I, Shimada K, Shimamoto K, Suzuki H, Takishita S, Tanahashi N, Tsuchihashi T, Uchiyama M, Ueda S, Ueshima H, Umemura S, Ishimitsu T, Rakugi H. The Japanese Society of Hypertension Guidelines for the Management of Hypertension (JSH 2009). Chapter 5. Treatment with antihypertensive drugs. Hypertens Res 2009 ; 32: 33-39.

30 Aota Y, Morimoto S, Sakuma T, Morita T, Jo F, Takahashi N, Maehara M, Ikeda K, Sawada S, Iwasaka T. Efficacy of an L- and N-type calcium channel blocker in hypertensive patients with neurovascular compression of the rostral ventrolateral medulla. Hypertens Res 2009; 32: 700-705.

31 Ogihara T, Kikuchi K, Matsuoka H, Fujita T, Higaki J, Horiuchi M, Imai Y, Imaizumi T, Ito S, Iwao H, Kario K, Kawano Y, Kim-Mitsuyama S, Kimura G, Matsubara H, Matsuura H, Naruse M, Saito I, Shimada K, Shimamoto K, Suzuki H, Takishita S, Tanahashi N, Tsuchihashi T, Uchiyama M, Ueda S, Ueshima H, Umemura S, Ishimitsu T, Rakugi $\mathrm{H}$. The Japanese Society of Hypertension Guidelines for the Management of Hypertension (JSH 2009).Chapter 12. Secondary hypertension. Hypertens Res 2009; 32: 78-90. 